\title{
PARIENTES PRÓXIMOS, PARIENTES LEJANOS UNA MIRADA ESTRUCTURAL AL SISTEMA DE PARENTESCO DEL GUARANÍ ANTIGUO
}

\author{
LEONARDO CERNO ${ }^{1}$
}

\begin{abstract}
RESUMEN
Este estudio propone una reconstrucción del sistema semántico del parentesco guaraní correspondiente a la fase inicial del contacto entre indígenas y europeos (siglo XVI). Para ello se emplea el método estructural aplicado a datos procedentes de las primeras fuentes lexicográficas disponibles, la mayoría del siglo XVII. El análisis se extiende además a las fuentes del tupinambá de la misma época, considerando la proximidad genética entre ambas lenguas y la consistencia semántica y formal entre los ítems léxicos. También son tenidos en cuenta datos etnográficos y lexicográficos de pueblos de lengua tupí-guaraní contemporáneos (kaiowá, mbyá guaraní, araweté) en vistas a comparar datos lingüísticos internos a esta familia lingüística, así como prácticas vinculadas a la organización social y el matrimonio. Los resultados confirman que el campo semántico del parentesco guaraní se organiza en torno a las dimensiones de generación, filiación, sexo del pariente, sexo del hablante y edad relativa del pariente. Por otra parte postulamos la existencia de otro rasgo, la "espacialidad", el cual, si bien no es distintivo a nivel estructural, es pertinente para la clasificación de subclases de parientes de acuerdo con el grado de distancia o proximidad social. Además, mostramos que esta hipótesis es consistente con algunos aspectos gramaticales y pragmáticos de la lengua.
\end{abstract}

PALABRAS CLAVE

Guaraní; Tupinambá; Parentesco; Semántica estructural

\section{PARENTES PRÓXIMOS, PARENTES DISTANTES. UM OLHAR ESTRUTURAL SOBRE O SISTEMA DE PARENTESCO DO GUARANI ANTIGO}

\begin{abstract}
RESUMO
Este estudo propõe uma reconstrução do sistema semântico do parentesco guarani, correspondente à fase inicial do contato entre indigenas e europeus (século XVI). Para tanto, utiliza-se 0 método estrutural aplicado a dados obtidos nas primeiras fontes lexicográficas disponíveis, a maior parte escritas no século XVII. A análise também abrange as fontes referentes ao tupinambá do mesmo período, considerando a proximidade genética entre as duas línguas e a consistência semântica e formal entre os itens lexicais. Também são levados em conta dados etnográficos e lexicográficos de povos contemporâneos de língua Tupi-Guarani (Kaiowá, Guarani Mbyá, Araweté), com 0 propósito de comparar dados linguísticos proprios desta família de línguas bem como identificar práticas derivadas da organização social e do casamento. Os resultados confirmam que o campo semântico do parentesco guarani se organiza em torno as dimensões de geração, filiação, sexo do parente, sexo do falante, e idade relativa do parente. Além disso sustentamos a existência de um outro traço, a "espacialidade" que, embora não seja distintivo em nível estrutural, é relevante para a classificação em subclasses de parentes, de acordo com o grau de distância ou proximidade social do indivíduo de referência. Finalmente, argumentamos que essa hipótese é consistente com alguns aspectos gramaticais e pragmáticos da língua.
\end{abstract}

PALAVRAS CHAVE

Guarani, Tupinambá, Parentesco; Semântica estrutural

${ }^{1} \mathrm{IESyH}$ - UNaM - Conicet. 


\title{
CLOSE RELATIVES, DISTANT RELATIVES \\ A STRUCTURAL LOOK AT THE KINSHIP SYSTEM OF OLD GUARANÍ
}

\begin{abstract}
The goal of this work is the reconstruction of the semantic system of Guaraní kinship terms corresponding to the early time of the contact between South American Indians and Europeans (16th Century). Based on the structural method we analyze lexicographic data proceeding from the oldest sources of this language, mainly written in the 17th Century. For the colonial sources our analysis extends from Guaraní to Tupinambá, language which has a near degree of genetic relatedness with Guaraní, and whose lexical items present a high degree of formal and semantic similarities. Modern sources (20th and 21st Century), coming from kaiowá, mbyá and araweté, allows in turn comparations of current linguistic data with those from the past, giving as well ethnographic information of Guaraní, particularly on social institutions related with kinship. The results of our analysis confirm that the semantic field of Guaraní kinship were organized throughout features like generation, patrilineality, sex of the kin, sex of the speaker and age of the kin. On the other hand, we postulate the existence of a further feature, "spatiality", which is not distinctive at the structural level, but relevant in the classification of kin in subclasses according it social proximity or distance. To prove these ideas we show structural facts at the semantic level, as well at the level of nominal morphology and pragmatics.
\end{abstract}

\section{KEY-WORDS}

Guaraní; Tupinambá; Kinship; Structural Semantics

\section{PARENTS PROCHES, PARENTS ÉLOIGNÉS. UN REGARD STRUCTUREL SUR LE SYSTĖME DE PARENTÉ DU GUARANI PRE-COLONIAL}

\section{RÉSUMÉ}

Cette étude propose une reconstruction du système sémantique de la parenté guarani correspondante à la phase initiale du contact entre indigènes et européens (XVlème siècle). Pour cela, on emploie la méthode structurale appliquée à des données procédant des premières sources lexicographiques disponibles, la plupart du XVIlème siècle. L'analyse s'étend en plus aux sources du tupinamba de la même époque, en considérant la proximité génétique entre les deux langues et la consistance sémantique et formelle entre les items lexiques. On tient compte aussi des données ethnographiques et lexicographiques de peuples de langue tupi-guarani contemporains (kaiowa, mbya guarani, arawete) dans le but de comparer des données linguistiques internes à cette famille linguistique, ainsi que des pratiques liées à l'organisation sociale et le mariage. Les résultats confirment que le domaine sémantique de la parenté guarani s'organise autour des dimensions de génération, filiation, sexe du parent, sexe du locuteur et âge relatif du parent. D'autre part, nous manifestons l'existence d'un autre trait, la "spatialité ", lequel, bien qu'il ne soit distinctif au niveau structural, est pertinent pour le classement de sous-classes de parents en accord avec le degré de distance ou proximité sociale. Du reste, nous montrons que cette hypothèse est consistante avec quelques aspects grammaticaux et pragmatiques de la langue.

MOTS CLÉS

Guarani ; Tupinamba ; Parenté ; Sémantique Structurale 


\section{INTRODUCCIÓN}

El objetivo del presente estudio es la reconstrucción de las estructuras del léxico del parentesco guaraní tal como habría existido en tiempos iniciales del contacto entre indígenas de lengua tupí-guaraní y europeos durante el proceso de colonización, es decir durante el siglo XVI. ${ }^{2}$ En este sentido nuestro análisis se basa en las primeras fuentes coloniales de esta lengua, las cuales consisten en diccionarios y vocabularios elaborados hacia la primera mitad del siglo XVII. Varios problemas, teóricos y metodológicos, deben ser explicitados en vistas a entender el alcance de este estudio así como sus limitaciones. El primero consiste en la validez científica de las fuentes, escritas en un contexto de colonización y atravesadas por la ideología de los lexicógrafos. El segundo toca a aspectos metodológicos, básicamente a la reconstrucción del punto de vista sincrónico de nuestros datos lingüísticos, punto de vista considerado necesario en toda descripción estructural. La tercera cuestión se refiere a la relación entre las estructuras léxicas y la "cultura", es decir, entre la organización de la experiencia colectiva que constituyen las lenguas, y otras manifestaciones de la vida social (organización política, económica, religiosa, etc., de los grupos humanos). Desarrollaremos estos problemas por separado.

Nuestras fuentes primarias se forman a partir de los registros lexicográficos de la obra de Ruiz de Montoya, padre de la Compañía de Jesús, quien reunió en una gramática, un vocabulario y un catecismo su experiencia con indígenas que hablaban un dialecto de la lengua guaraní en la región del Guairá. Se trata como se sabe de las fuentes más completas del guaraní colonial, aunque para el trabajo científico cuenta con la desventaja de que no fueron elaboradas con fines de conocimiento "objetivo", sino para la evangelización de los indígenas y su relocalización en pueblos o reducciones (donde vivirían un proceso de transformación cultural). Así, en la obra del padre limeño muchas palabras fueron codificadas con significados diferentes al nativo, o incluso con significados nuevos, en el intento de fijar expresiones que no distorsionaran la visión teológica e ideológica del cristianismo. En los términos del parentesco el sesgo de las fuentes se manifiesta no sólo en su intento de adecuación al modelo de familia cristiana occidental, sino también en la traducción de los vocablos al español. En este proceso ocurre una pérdida importante de acepciones y sentidos nativos. Para teindy, por ejemplo, Montoya traduce "hermana, y prima hermana [del varón]", pero la expresión española "prima hermana" desatiende un límite funcional establecido por la oposición de teindy con jetipe, prima cruzada del varón, con lo que teindy indica "prima" pero únicamente en sentido de prima paralela. Para evitar este tipo de desfasajes

\footnotetext{
${ }^{2}$ Agradezco a mi maestro y amigo Wolf Dietrich la amable lectura y los comentarios que ha hecho sobre este trabajo. Pese a todo, los errores e incertezas que de todos modos persisten son de mi entera responsabilidad.
} 
semánticos, que tocan a la mayoría de los términos del parentesco (CERNO, 2018, en prensa), recurrimos a la comparación con otras fuentes antiguas, principalmente con los vocabularios del tupinambá, lengua próximamente emparentada con el guaraní y hablada en la costa atlántica del Brasil en la misma época. Por otra parte recurrimos a fuentes secundarias, configuradas con datos lingüísticos y etnográficos de varios pueblos guaraníes contemporáneos, concretamente de grupos del guaraní meridional (principalmente kaiowá, también conocidos como paĩ tavyterã, y mbyá guaraní), quienes habitan prácticamente la misma región histórica de los guaraníes con quienes trabajaron Montoya y otros jesuitas del Paraguay, enriqueciéndolas además con fuentes de un grupo amazónico de lengua tupíguaraní, el araweté. Ésta última fuente contemporánea tiene la ventaja de presentar un análisis exhaustivo del parentesco, así como de referirse a un pueblo de lengua tupí-guaraní todavía poco transformado por la sociedad envolvente (VIVEIROS DE CASTRO, 1993). En conclusión, el problema del sesgo ideológico de las fuentes antiguas fue controlado con el auxilio de los datos lingüísticos y etnográficos de otros grupos tupí-guaraníes, que sirvieron para aplicar comparaciones, descubrir rangos de variación y formular hipótesis diacrónicas.

Nuestra lengua objeto de estudio es el guaraní de la fase inicial de la conquista. La manifestación más directa de esta lengua son los lemas de diccionarios y los ejemplos que los acompañan. Estos fueron escuchados y anotados de memoria por Ruiz de Montoya en circunstancias diferentes, y tomados de hablantes pertenecientes a parcialidades también diferentes. El grado de unidad lingüística de los varios dialectos guaraníes de la época, no puede, no obstante, ser cuestionado. Evidencias históricas y lingüísticas permiten sostener que el grado de diferenciación dialectal no fue grande. Por un lado, diversos testimonios de actores de la época dan cuenta de la existencia de un área lingüística guaraní poco fragmentada, la cual se extendía al menos desde las cuecas del río Paraná y Paraguay hasta la costa atlántica del Brasil (SCHMIEDL, [1567] 2008; MONTOYA, 1639a; MELIÀ, 2003). ${ }^{3}$ Por otra parte, los datos lingüísticos permiten observar una gran semejanza entre los ítems léxicos del guaraní de Montoya y del tupinambá de la costa del Brasil, y especialmente entre los términos de parentesco. De acuerdo a estas semejanzas, las estructuras y funciones que son

\footnotetext{
${ }^{3}$ Así el testimonio del soldado Ulrich Schmidel, quien tuvo la oportunidad de comparar el tupí de São Vicente con el dialecto de los Carios de Asunción hacia mediados del siglo XVI: "Auch diese Tupi sprechen eine Sprache gleich wie die Carios; es ist nur eine kleine Differenz unter ihnen beiden in der Sprache [...] También esos tupíes hablan una lengua igual a la de los Carios; hay sólo una pequeña diferencia entre ambos al respecto de la lengua" (SCHMIEDEL, [1567] 2008, p. 92, mi traducción). Por su parte Montoya también percibió, al parecer, más las semejanzas entre los diferentes dialectos de la época que las diferencias: "tã vniuersal [es la lengua], que domina ambos mares, el del Sur por todo el Brasil, y ciñendo todo el Perù, con los dos mas grandiosos ríos que conoce el Orbe, que son el de la Plata, [...] y el gran Marañon ..." (MONTOYA, 1639a, p. s/p). A los padres religiosos... Así también Alonso Barzana unos años antes refiere: "los tres padres que vinieron del Brasil saben muy bien el Guaraní, muy poco diferente del Tupi", (MELIÀ, 2003, p. 75).
} 
nuestro objetivo, y que existen en el plano de la lengua funcional (sincrónica) (COSERIU, 1986), pueden reconstruirse con ciertos cuidados y considerarse válidas.

El problema de la relación entre las estructuras léxicas y la "cultura", y en particular entre el léxico del parentesco y las estructuras de la organización parental (y, en fin, entre estas últimas y ciertas pautas culturales como el matrimonio, la descendencia y la residencia), abarca en el campo de la antropología una larga tradición de estudios y discusiones (BOSSERT et al., 2012, p. 26). En lo que hace al parentesco tupí-guaraní, varios modelos han sido propuestos ya desde la década de 1940, buscando extender el alcance de tipologías formuladas para otros grupos humanos, aunque no sin fuertes desacuerdos (MARQUES PEREIRA, 1999, p. 27; LARAIA s/a, para una introducción en las polémicas). Para los años '70, Laraia propone un modelo de la estructura de parentesco tupí basada en datos etnográficos y en trabajos de campo, el cual representa una nueva fase interpretativa que busca desprenderse de modelos importados (LARAIA s/a; LARAIA. 1987; MARQUES PEREIRA 1999, p. 38). En la actualidad, pese a todo, las discusiones acerca de una tipología adecuada al parentesco tupí-guaraní siguen vigentes (BOSSERT et al., 2012, p. 54). En esta contribución no podemos hacer una referencia precisa a estas discusiones, pues nuestro punto de vista es sobre todo lingüístico y debemos centrarnos en el plano del significado. No obstante no queremos perder de vista las consecuencias etnográficas del sistema de parentesco guaraní tal como lo hemos reconstruido, y algunas referencias a formas de organización social y reglas de intercambio serán efectuadas.

\section{FUENTES DE DATOS Y PROCESO DE ANÁLISIS}

Las fuentes primarias (guaraní antiguo) se exponen abajo junto con las fuentes secundarias (tupí y variedades del siglo XX/XXI). Con respecto a las primeras, a los conocidos Tesoro (1639) y Arte y Bocabulario de la lengua guaraní (1640a) de Montoya se agrega el Catecismo (1640b), concretamente la sección llamada "Nombres de parentesco" (1640b, p. 318-324), con información indispensable para nuestra tarea. Los registros del tupinambá (a partir de aquí "tupí") se componen principalmente del Catecismo de Araujo (1686), que también presenta una lista de nombres de parentesco (ARAUJO, 1686, p. 267-274), así como del Arte de Anchieta ([1874] 1595, p. 17-21) y del vocabulario de Rodolfo García, este último elaborado a partir de diferentes fuentes antiguas (GARCíA, p. 1944). Completan el corpus del tupí el Vocabulario na lingua brasilica (siglo XVII, editado por PLINIO DA SILVA AYROSA, 1934) y el documento de Joseph de Anchieta Informações, que incluye una importante descripción de la teoría nativa del parentesco (ANCHIETA, 1846). Las fuentes contemporáneas se componen del dialecto kaiowá, tomado de los trabajos de Marques Pereira (1999) y de Melià, Grünberg y Grünberg ([1976] 2008), y del dialecto mbyá, 
procedente de la tesis de De Mello (2006, la cual incluye también el parentesco de los guaraní ñandeva), y del Atlas Lingüístico Guaraní Románico, Tomo II, "Léxico de parentesco" (ALGR, 2015). Por último los datos del dialecto araweté, empleado también como fuente secundaria, proceden de Viveiros de Castro (1993). El conjunto de fuentes, con las abreviaturas que se emplearán en este trabajo, se ofrece a continuación:

\section{Fuentes}

Siglo XVII

Guaraní

antiguo

Siglo XVII

Tupí

\section{Ruiz de $M$}

Ruiz de Montoya, Vocabulario de la lengua guaraní

Ruiz de Montoya, Catecismo de la lengua guaraní

\section{Abreviatura \\ Mo.T \\ Mo.V \\ Mo.C}

Anl

$A \cap A$

AR

AY

GA
Siglo XX/XXI

Kaiowá

Mbyá

Araweté
Anchieta, Arte de Grammatica da lingua mais usada..

Araujo, Catecismo Brasilico

[Ayrosa], Vocabulario na lingua brasilica

García, Nomes de Parentesco em língua tupí
$M P$

MGG

DM

ALGR

VC

Nuestro análisis consistió en una etapa semasiológica, una etapa comparativa y una etapa sistémica. La primera buscó la identificación de cada uno de los ítems léxicos en cada variedad o fuente empleada, seguida de la descripción externa del conjunto de sus acepciones (o variantes del significado). Por ejemplo, un término como tuty, identificado como "hermano de la madre" y "primo hermano de la madre" por Montoya, involucra un conjunto amplio de acepciones, una para "hermano de la madre", descripta como "Hno.Ma", ${ }^{4}$ y varias para "primo de la madre", entre las que se deben consignar las diferentes filiaciones de los primos maternos: "Ho.Hno.Pa.Ma, Ho.Hna.Pa.Ma, Ho.Hno.Ma.Ma, Ho.Hna.Ma.Ma". La etapa comparativa incluyó el cruce de fuentes y el recurso a la interpretación del material etnográfico, con lo cual la descripción del significado puede ajustarse identificando lagunas, generalizaciones y posibles errores en las fuentes antiguas, a la vez que descubriendo tendencias generales del sistema. Por ejemplo, en el caso de tuty, fuentes contemporáneas permiten inferir que, en tanto "primo de la madre", el vínculo en la época de Montoya debió restringirse a los primos paralelos de la madre, con lo que la estructura semántica del concepto se reduce a sólo tres acepciones, "Hno.Ma, Ho.Hno.Pa.Ma, Ho.Hna.Ma.Ma". El tercer momento corresponde a la visión sistémica (y onomasiológica), donde los términos

\footnotetext{
${ }^{4}$ Las abreviaturas empleadas en este artículo para las relaciones de parentesco son las siguientes: $\mathrm{Pa}=$ padre, $\mathrm{Ma}=$ madre, $\mathrm{Hno}=$ hermano, $\mathrm{Hna}=$ hermana, $\mathrm{Ho}=$ hijo, $\mathrm{Ha}=$ hija, Ea = esposa, $>=$ mayor, $<=$ menor. El punto entre dos abreviaturas indica relación de genitivo, o "del/ de la". Ho.Hna.Pa se lee "hijo de la hermana del padre".
} 
muestran relaciones de solidaridad u oposición mutua de acuerdo a categorías generales y distintivas. Éstos corresponden, de acuerdo con la teoría, a la concepción nativa del parentesco. Volviendo al caso de tuty, los rasgos funcionales de "generación G+1 G0", "no patrilineal", y "varón", permiten explicar la diversidad de acepciones en las diferentes lenguas tupí guaraníes de nuestras fuentes.

\section{LA VARIACIÓN DEL SIGNIFICADO EN LOS TÉRMINOS DE PARENTESCO}

A continuación especificamos el uso particular de los términos de parentesco guaraníes en las diferentes variedades investigadas, detallando sus acepciones comunes y diferenciadas.

1. Tamõi. En las fuentes históricas (guaraní, tupí) es "abuelo", en sentido de Pa.Pa y Pa.Ma, sin indicación de un alcance más general, a otros hombres de G+2. Esto último ocurre en cambio en fuentes contemporáneas del kaiowá y el araweté, donde se extiende también a otros parientes de la G+2 como el Hno.Pa.Pa, Hno.Pa.Ma, etc., a inferir por la información disponible (MP, p. 68; VC, p. 156). Рara el mbyá guaraní no hay datos en relación al alcance más extenso del término.

2. Jarýi. Ma.Pa y Ma.Ma, es decir "abuela", en las fuentes históricas y sin indicación de un alcance más general. De las fuentes contemporáneas (kaiowá, araweté) se infiere su uso para a otros parientes de la G+2, como la Hna.Pa.Pa, Hna.Pa.Ma, etc., (MP, p. 68; VC, p. 156). Рara el mbyá guaraní no hay datos en relación al alcance más extenso del término.

3. Túba. Vale para varios vínculos de parentesco, pero principalmente "padre". Mo.C (p. 323), brinda el alcance más amplio, que incluye Pa, Hno.Pa, Hno.Pa.Pa, y al Ho.Hno.Pa.Pa. Con estos usos menos Ho.Pa.Pa en tupí (AR, p. 273). También parece haberse usado en tupí para Hno.Ma.Ea, Ho.Hno.Ma.Ea (GA, p. 188). En las fuentes contemporáneas, sólo "padre" (MP, p. 68; VC, 156; DM, p. 86). Así el término antiguo habría alcanzado al padre, sus hermanos y primos paralelos, y otros parientes varones de la $G+1$.

4. Tuby. Término que no existe en tupí (AR; GA; AY; AnA), es en guaraní el Hno.Pa (Mo.T., Mo.C., Mo.V). También Hno.Pa en las etnografías contemporáneas (MP, p. 68; DM, p. 86). La extensión a los primos paralelos del padre (Ho.Hno.Pa.Pa; Ho.Hna.Ma.Pa) se infiere del uso actual en araweté (VC, p. 157), y también de las definiciones de las fuentes antiguas para jaiche. La inexistencia de tuby en tupí antiguo indica que habría sido una creación en el guaraní, y su posible origen en la voz túb(a) 'padre' más un modificador 'y 'intensificador/diminutivo' indica que la oposición surge en una etapa posterior al uso de túba para todas esas funciones. 
5. Jaiche. Hermana y prima del padre (Mo.C; definición menos extensa en Mo.T.; Mo.V), también para el tupí (AR, p. 268; GA, p. 183). Como en el caso de tuby, el uso del término en araweté indica que se aplica a las primas paralelas. Sin mayor información que Hna.Pa en otras fuentes contemporáneas.

6. Sy. Sólo como "madre" en todas las fuentes. La palabra es polisémica pues también significa "fonte, origem, manancial" (AR; GA) у "raíz de donde proviene la cosa" (Mo.T). En varios grupos tupí es posible el uso de sy también para la Hna.Ma, (LARAIA s/a, p. 11-12).

7. Sy'y. Hermana mayor de la madre según Montoya (en Mo.C., corresponde al habla masculina; en Mo.V y Mo.T. sin marca para sexo del hablante), lo mismo en las fuentes del tupí, donde su reflejo cyyra no indica edad relativa sino sólo Hna.Ma y también "madrastra" (GA, p. 184; AR, p. 268). También en las fuentes contemporáneas del kaiowá y el mbyá, sólo Hna.Ma (MP, p. 68; DM, P. 86). Para el araweté se aplica también a las primas paralelas de la madre (VC, p. 157)..$^{5}$ De aquí que, como en tuby, jaiche, etc., pensamos que este es el alcance más antiguo del término, es decir que engloba a hermanas y primas paralelas de la madre.

8. Sy'yky. Hermana menor de la madre en las fuentes antiguas del guaraní (Mo.C; Mo.V; Mo.T). Рara el tupí AR no registra el término, sí GA citando a Batista Caetano. Tampoco existe en las fuentes contemporáneas, donde sólo se registra sy'y (arawete hi di). Es una palabra compuesta a partir de sy'y'Hna.Ma' y ky'tierno', y por lo tanto una innovación posterior al uso de sy para Ma. y Hna.Ma, y de sy'y para Hna.Ma. Como para $s y^{\prime} y$, también extendemos el alcance de sy'yky para las primas paralelas de la madre.

9. Tuty. Hermano y primo de la madre, así como los hijos varones de éstos (Mo.T; Mo.C; AR, p. 273; GA, p. 188; AnA, p. 20). Entre los kaiowá y mbyá actuales, sólo Hno.Ma. Por el uso de toti en araweté creemos que el término abarcó en guaraní antiguo también a los primos paralelos de la madre (VC, p. 157 y nota 3). Con el significado de Ho.Hno.Ma sólo en las fuentes antiguas. No vemos inconveniente en postular que el uso alcanzó también a los hijos de los primos paralelos de la madre.

10. Tyke’y. Según Montoya, hermano del varón, mayor que Ego (Mo.T; Mo.C). Para el tupí también existe la acepción de primos del varón, si Ho.Hno.Pa (AR, p. 272273; GA, p. 189), y si mayor que Ego. También se llama tykyéyal sobrino Ho.Hno mayor, si es mayor que Ego (Mo.T; AR, p. 272-273). Por las fuentes del araweté y del kaiowá confirmamos el uso de los reflejos de tyke'y también para los primos paralelos del

\footnotetext{
${ }^{5}$ Inferido a partir de la información que da Viveiros de Castro. Para Hi d’ da "M[other] Z[sister], etc.", donde el "etc." puede referirse al hecho de que anĩ 'Z [sister]' es también "FBD [Father brother daughter] y MZD [mother sister daughter]" (VC, p. 157). Lo mismo vale para el hermano de la madre.
} 
varón, es decir para Ho.Hno.Pa, e Ho.Hna.Ma, si mayores que Ego (VC, p. 157; MP, p. 69).

11. Tyvy. Hermano del varón, menor que Ego, en guaraní y en tupí (Mo.T; Mo.C; GA, p. 189; AR, 272). En tupí el término tiene una especificación con -ky'tierno', ya vista en sy'yky. tyvykyhermano "menor de todos" (AR, p. 272). Montoya registra esta palabra pero la considera sinónimo de tyvy. Por las fuentes del araweté y del kaiowá confirmamos el uso de los reflejos de tyvy también para los primos paralelos del varón menores que Ego. En mbyá guaraní constan tyke'y y tyvy para Hno>Ego y Hno<Ego respectivamente, pero la información es confusa respecto a su extensión para los primos paralelos. Parece que esta distinción se ha perdido y que primos paralelos y cruzados se engloban bajo las formas: tyke'y, tyvy (DM, p. 86) o che ra'y kirĩ (ALGR, p. 276).

12. Teindy. Hermanas y primas del varón según las fuentes antiguas (Mo.T.; Mo.C.; AR, p. 272; GA, p. 188). El significado de esta palabra en kaiowá y en araweté modernos incluye a las primas paralelas (MP, p. 69; VC, p. 157). En mbyá guaraní parece que la oposición se ha perdido, ya que no se distinguen las primas cruzadas de las paralelas, y todas estas mujeres parientes son designadas con teindy (DM, p. 86; ALGR, p.154 y 276-284).

13. Jýra. Primo cruzado y sobrino cruzado del varón. Hijo de la hermana del varón, y "de su tía" según Montoya (Mo.C; Mo.V.; en Mo.T sólo Ho.Hna), sin especificación del vínculo (patri/matrilineal) de la tía. En algunas fuentes del tupí, con el mismo resultado al que se agrega Ho.Ma.Pa, Ho.Ma.Ma, así como "entenado" del varón (AR, P. 274; GA, p. 189). ${ }^{6}$ En kaiowá es el Ho.Hna, el Ho.Hno.Ma y el hijo de los primos y primas cruzados (MP, p. 69). En araweté es Ho.Hna y "any man whom 10 [hermana del varón] calls memi ['hijo']" (VC, p. 158). La acepción para Ho.Hno.Ma no se registra en esta lengua. Jýra es término del habla masculina en la mayoría de las fuentes. Al parecer la base común a estas acepciones es la noción de "descendiente varón de una mujer de la familia de Ego (Ho.Hna; Ho.Hna.Pa), o de un hombre de la familia de la madre de Ego (Ho.Hno.Ma)". En mbyá guaraní la terminología para los hermanos y primos paralelos y cruzados se ha fusionado y esas relaciones ya no se distinguen lexicalmente (DM, P. 86; ALGR, p. 267). No obstante la distinción existe a nivel de los sobrinos. Así jýra se registra para 'sobrino del varón' y jýra kyrĩpara 'hijo de las hermanas del varón' (ALGR, p. 249 y 251).

14. Jetipe. Sobrina cruzada y prima cruzada del varón. Hija de la hermana del varón, o hija "de su tía" según Montoya (Mo.C; Mo.T), sin especificación del vínculo (patri/matrilineal) de la tía, en el tupí con el mismo resultado (AR, p. 269; GA, p. 185). En

6 "E juntamente o tio filho da avó do varão" (AR, p. 274), no sabemos si Ho.Ma.Pa o Ho.Ma.Ma, o ambos. 
las fuentes modernas jetipe es una mujer de la $\mathrm{G}-1$, hija de las hermanas o primas cruzadas de Ego (VC, p. 158; MP, p. 69), en kaiowá también de la G0 como prima cruzada, Ha.Hna.Pa o Ha.Hno.Ma, en mbyá la 'sobrina del varón' (ALGR, p. 249 y 261). "Su tía", como escribe Montoya, debe referirse así a la Hna.Pa y no a la Hna.Ma. Jetipe es palabra de uso masculino. Parece que el alcance más general del término podría ser "descendiente mujer de una pariente mujer de Ego varón (Ha.Hna; Ha.Hna.Pa), o de un varón emparentado con la madre de Ego (Ha.Hno.Pa)". Pese a todo no hay indicación en las fuentes antiguas sobre si incluye a la Ha.Hno.Ma. La incluimos por ser la figura del Hno.Ma un dador de esposas en la tradición guaraní, y por su uso en kaiowá moderno. De estas parientes jetipe pensaban los tupíes "que thes pertencem [...] para as poder ter por mulheres" (Anl, p. 259).

15. Kyvy. Hermano y primo de la mujer (Mo.T.; Mo.C.), si mayor que Ego femenino, con el mismo resultado para el tupí (AR, p. 269; GA, p. 185). En las fuentes del kaiowá y el araweté actual se explicita la extensión a los primos paralelos, Ho.Hno.Pa, Ho.Hna.Ma, (MP, p. 69; VC, p. 158). Рara el mbyá, donde al parecer se ha perdido la diferenciación léxica entre primos paralelos y cruzados, el término vale para ambas clases de primos (DM, p. 86; ALGR, p. 276).

16. Kyvyky. Montoya registra sólo "hermano menor" de la mujer (Mo.T.; Mo.C.), pero debe ser también "primo" menor que Ego femenino, siguiendo el tupí (AR, p. 269; GA, p. 185). En las fuentes del kaiowá y el araweté actual se explicita el uso para los primos paralelos, Ho.Hno.Pa, Ho.Hna.Ma, (MP, p. 69; VC, p. 158). Para el mbyá, donde al parecer se ha perdido la diferenciación léxica entre primos paralelos y cruzados, el término vale para ambas clases de primos (DM, p. 86; ALGR, p. 276). Kyvykyes sin duda un compuesto a partir de kyvy 'hermano de la mujer' y ky, 'tierno', de aquí 'hermano menor' de la mujer.

17. Tyke. En Montoya sólo "hermana mayor" de la mujer (Mo.T.,;Mo.C.), en tupí también "primas" (AR, p. 273; GA, p. 189). Por los datos del kaiowá y el araweté moderno sabemos que "primas" se refiere a las primas paralelas de la mujer (MP, p. 69; VC, p. 157). Para el mbyá, donde al parecer se ha perdido la diferenciación léxica entre primas paralelas y cruzadas, el significado de tyke y kypy'y vale para ambas (DM, p. 86; ALGR, p. 276).

18. Kypy'y. Hermana, prima y también "sobrina menor" de la mujer en Montoya (Mo.C, Mo.T), con el mismo resultado en tupí (AR, p. 270; GA, p. 186). Por los datos del kaiowá y el araweté moderno sabemos que "primas" se refiere a las primas paralelas de la mujer (MP, p. 69; VC, p. 157). Para la acepción de "sobrina" no hay información en sentido de Ha.Hno o Ha.Hna. Lo mismo que para tyke'y, como 'sobrino, hijo del hermano del varón, mayor a Ego', kypy'y debe referirse a mujeres mayores a Ego 
femenino que son hijas de ciertas hermanas de Ego femenino. Así en su reflejo en tupí (pyky'ýra, AR, ibid).

19, 20. Ta'y, tajy. Hijo e hija del varón, de su hermano, y de su "primo", en guaraní y en tupí antiguos (Mo.T.; Mo.C.; AR, p. 271; GA, p. 186-187). Por las fuentes del kaiowá y el araweté sabemos que "primo" se refiere a los primos paralelos del varón (MP, p. 70-72; VC, p. 158). En el mbyá se registra el uso de lo término ra'y kirĩ para los hijos e hijas de los hermanos varones del varón (ALGR, p. 249).

21. Memby. Término general para hijo e hija de la mujer. Montoya vacila en consignar el uso de "sobrino/a", en tanto Ho.Hna., Ha.Hna, de la mujer (Mo.C; Mo.T.) El tupí antiguo por su parte parece haber distinguido entre membyra Ho., Ha de la mujer, membyraycé Ho.Hna, y membycuhnã Ha.Hna de la mujer (AR, p. 269; GA, p. 185). En kaiowá, mbyá y araweté modernos, en cambio, puede usarse para Ha/Ho de la mujer y para Ha.Hna/Ho.Hna de la mujer (MP, p. 70-72; DM, p. 87; VC, p. 158). En kaiowá actual el término no alcanza a los hijos e hijas de las primas paralelas, que caen bajo el concepto de pẽng (MP, p. 70-72). El concepto de memby recibe modificadores para género natural, hijos/sobrinos memby raty, memby kuimba'e, memby ava, o hijas/sobrinas memby kuña, en todas estas lenguas. El mbyá diferencia entre Ho. e Ha., e Ho.Hna, Ha.Hna, con el modificador kyrỹ (o kuri) en memby kyrỹ, Ho.Hna, Ha.Hna (DM, p. 87; ALGR, p. 249).

22. Pẽng. Hijo e hija de los hermanos de la mujer (Mo.T; sobre todo M.V; con un probable error en Mo.C, en tupí "sobrinho da fêmea, primeiro filho de seu irmão";AR, p. 270; lo mismo en GA, p. 186). En kaiwa el significado se extiende a los hijos de todos los primos, paralelos y cruzados, en araweté sólo a los hijos de hermanos y primos paralelos (MP, p. 71-72; VC, p. 158). Nos parece que el uso en kaiowá moderno corresponde a una evolución posterior, en donde se perdió la oposición "hijo/hija de hermanos y primos paralelos de la mujer" vs. "hijo/hija de primos cruzados de la mujer", oposición que suponemos es antigua. Para el mbyá no hay muchos datos sobre el alcance del término y sólo sabemos del uso de pẽ para Ho.Hno, Ha.Hno de la mujer (DM, p. 87; ALGR, p. 249 y 253).

23. Temymyno. Nieto y nieta del varón en las fuentes antiguas (Mo.T; Mo.V; AR, p. 272), en las fuentes modernas el concepto se extiende a todos los varones y mujeres de la G-2 Ho.Ho, Ha.Ho, Ho.Ha, Ha.Ha, tanto propios como de los hermanos, de los primos paralelos y de los cruzados (MP, p. 172; VC, p. 158). Para el mbyá la información sólo se refiere a nieto y nieta del varón', sin noticia sobre extensiones posibles (DM, p. 87; ALGR, p. 228-229) 
24. Temiarirõ. Nieto y nieta de la mujer, con las mismas observaciones que dimos para temymyno.

\section{LA ORGANIZACIÓN DEL CAMPO SEMÁNTICO DEL PARENTESCO}

Para el análisis semántico estructural interesan las relaciones establecidas entre los lexemas que designan relaciones parentales, los cuales, de acuerdo con la teoría, involucran oposiciones paradigmáticas formadas a partir de rasgos comunes y rasgos distintivos.

\section{CLASES DE PARIENTES}

Lo primero que debe probarse es la existencia misma de un campo semántico propio del parentesco. En guaraní y el tupí antiguos existen varias palabras para designar parientes. Las principales y con sentido general son ana 'pariente, parentesco', maranunga 'pariente, parentela' (Mo.C; Mo.T; Mo.V; AR; GA). Otras palabras con este significado se caracterizan por presentar una estructura polisémica, y en algunos casos por subsistir en ellas rasgos de composición a partir de lexemas simples. Observemos por ejemplo tetãmbipe palabra del hombre para 'pariente mujer' y ta'yse palabra de la mujer para 'pariente varón', la primera del guaraní, la segunda del guaraní y del tupí (Mo.T; GA, P. 187; AR, p. 270-271). La primera se forma a partir de tetã 'pueblo", con lo cual la noción de parentesco (o "pariente mujer del varón") se muestra asociada a la noción de espacio social. La segunda expresión se forma con ta'y que significa 'hijo del varón' y también 'semen', hecho que nos parece indica una relación entre parentela masculina y la capacidad, exclusiva del varón, de dejar descendencia. Ta'yse con esto designa, si tenemos en cuenta el étimo ta'y, un pariente de la mujer en tanto "varón, desciende de un varón, y capaz de procrear parientes varones". 8 Al caso viene aquí la voz tuja'og 'pariente', formada a partir de tu(b) 'padre' y ja'o 'separación', es decir "alguien separado de mi padre", indicando la patrilinealidad como criterio para delimitar ciertos parientes. Otros lexemas asocian el parentesco a la práctica del intercambio o trueco, o bien al aumento poblacional del grupo (logrado vía alianza y matrimonio).

\footnotetext{
${ }^{7}$ En el Tesoro se lee para tetãmbipe: "parienta, corresponde a muger pariẽta. Cheretâmbipé, dize el varon a las mugeres de su pueblo, y incluyendo algo de parentesco, y lo dizen a sus mismas hermanas. Lo mismo es, che cuñâ (Mo.T., p. 383r-383v). Por su parte ta'yse, para el guaraní: "Pariente de solo la muger al varon, y ella sola lo usa. Cherayce, mi pariente, de mi parcialidad, o parentela, varon" (Mo.C). En tupí: "Parente da geração, o nação, da femea” (AR, p. 271).

${ }^{8}$ Un documento de Anchieta muestra que, entre los tupinambá, la teoría nativa del parentesco fue patrilineal y la descendencia unilineal, asociada sólo al hombre: "têm para si o parentesco verdadeiro, vem pela parte dos pais, que são os agentes; e que as mãis não são mais que uns saccos, em respeito dos pais, em que se criam as crianças [...]" (ANCHIETA, 1846, p. 259-260). La continuidad estructural entre el léxico de parentesco de tupíes y guaraníes, además de otras similitudes etnográficas, nos permiten extender esta teoría también a los guaraníes.
} 
Notablemente estos lexemas agregan al contenido "pariente" el rasgo de "lejano". Un caso es la voz mu, definida como "pariente lexano, y amigo, con quien trata y conversa" y también como "amistad, parentesco, contrato, trueco adinuicem, contrario" (Mo.C.; Mo.T.; respectivamente). ${ }^{9}$ Otro es el lexema tetarã, formado con teta 'cantidad, muchos' y el sufijo de aspecto prospectivo -rã, y definido como "que me ha de aumentar, dizen todos a sus parientes lexanos, y a los que son de su nación" (Mo.T., p. 383).

Pese a que no puede decirse que el significado de los lexemas para "pariente" esté firmemente estructurado, el conjunto de términos con este sentido se organiza en torno a ciertos contenidos recurrentes. Estos son la filiación, el sexo del pariente (involucrando el sexo del hablante), y la distancia espacial o social (pariente próximo o lejano). Con respecto a la filiación, existe a su vez un elemento léxicamente marcado que es la patrilinealidad (tuja'og, ta'yse). Por su parte el contenido de "distancia" coocurre con elementos vinculados al matrimonio y la alianza ( $m u$, tetara). Nos parece que en esta organización están presentes algunas de las dimensiones principales del campo semántico del parentesco guaraní. ${ }^{10} \mathrm{~A}$ continuación un esquema:
Pariente (no marcado)
i) Pariente + Filiación (patrilineal)
ii) Pariente + Sexo (del hablante y del pariente)
iii) Pariente + Espacialidad (próximo, distante)

\author{
and, maranunga \\ tuja'og, ta'yse \\ tetãmbipe, ta'yse \\ tetarã, mu, tetãmbipe
}

Por su parte las fuentes históricas y etnográficas sobre los grupos tupí-guaraníes apoyan la idea de una interacción entre la concepción nativa parentesco, los roles del hombre y la mujer y la organización espacial. El concepto de téýio "familia extensa" es clave para comprender la sociología de parentesco. ${ }^{11}$ Los guaraníes habitaban en malocas donde

\footnotetext{
${ }^{9}$ En tupí sólo la primera parte de la definición de García se aproxima a la de Montoya: "Aliado, coligado, aparentado; tanto significa parentesco, como pessoa da mesma geração" (GA, p. 186). La definición de Araujo es: "Nome genérico, que significa parentesco geralmente, ou pessoa da mesma geração" (AR, p. 270). Se observa que para este autor el término es sólo un sinónimo de 'pariente', sin indicación de grado de proximidad.

${ }^{10}$ La dimensión de generación no está codificada en estos lexemas, aunque sí en expresiones que integran el campo semántico de las edades y que en parte se forma con términos de parentesco para "abuelos": tamõi 'abuelo/anciano', ava 'hombre adulto', kuimba'e 'muchacho', etc., para el varón, jarýi 'abuela/anciana', kuña 'mujer adulta', kuñambuku'muchacha', etc., para la mujer.

11 Montoya define te'ýi como "compañía, parcialidad, genealogía" (Mo.T.), en tanto en Conquista espiritual describe las aldeas guaraníes como un grupo de "casas": "Viuiendo a su antigua vsança en montes [...] en tres, quatro, o seis casas solas, separados a legua, dos, tres, y mas vnos de otros" (MONTOYA, 1639b, p. 6). La relación entre varios te'ýi configuraba un espacio social que en tiempos modernos se conoce como tekoha: "cuando varios te'ýi se asociaban, 5, 6 o más, formábase una consciencia socio local unitaria, el vínculo 'aldeano', teko'a' (SUSNIK, 1983, p. 136, apud MURA 2006, p. 36). Entre los kaiowá actuales el tekoha es concebido espacialmente, como "lugar donde vivimos según nuestras costumbres" (MELIÀ, GRÜNBERG Y GRÜNBERG, [1976] 2008, p. 131). Véase (MURA 2006, p. 36-48) para un análisis histórico y contemporáneo de la organización espacial y política de los guaraníes.
} 
vivía una familia extensa, la cual compartía el espacio de la aldea y roza con otros te'ýi asociados. Entre varios téýise promovían prácticas de intercambio y cooperación económica y guerrera, y tenían lugar matrimonios preferenciales (normalmente entre Ha.Hna y Hno.Ma). Las familias extensas contaban con un jefe o cacique, normalmente un adulto o un anciano, y se componían de varias unidades sociales menores. Estas últimas se formaban por los grupos nucleares de parientes consanguíneos y sus afines (esposo y esposa/s y descendencia). Pese a que las fuentes dan información diversa en cuanto a la residencia de los esposos después del matrimonio, nos parece que la tendencia general fue de patrilocalidad, siendo la uxorilocalidad una solución también posible aunque menos difundida.

\section{RASGOS PRINCIPALES DE LOS TÉRMINOS DE PARENTESCO}

El sistema de parentesco guaraní, como suele ser normal en toda lengua, cuenta con rasgos más productivos que otros para crear las diferentes funciones léxicas. Así, junto con los rasgos funcionales más importantes, presentes en casi todas las oposiciones, aparecen otros que actúan sólo en dominios más pequeños o específicos. Nuestra hipótesis es que las relaciones entre los rasgos más generales y los más específicos está motivada en parte por el contenido cultural de la "espacialidad". En términos operativos, la espacialidad se manifiesta en subespecificaciones que actúan por debajo del nivel de la filiación y del sexo del pariente. En tanto generación, filiación, el sexo del pariente, el sexo del hablante, colateralidad, etc., constituyen los elementos distintivos, la dimensión de espacialidad es un rasgo "indexical", que surge del valor que adoptan aquellos elementos. La espacialidad vehiculiza significados concomintantes, es decir, el sentido no está presente en las estructuras, pero puede inferirse a partir de la relación entre éstas y las expectativas culturales del contexto.

\section{LA GENERACIÓN G+1}

El primer subsistema que presentamos corresponde a la generación G+1:

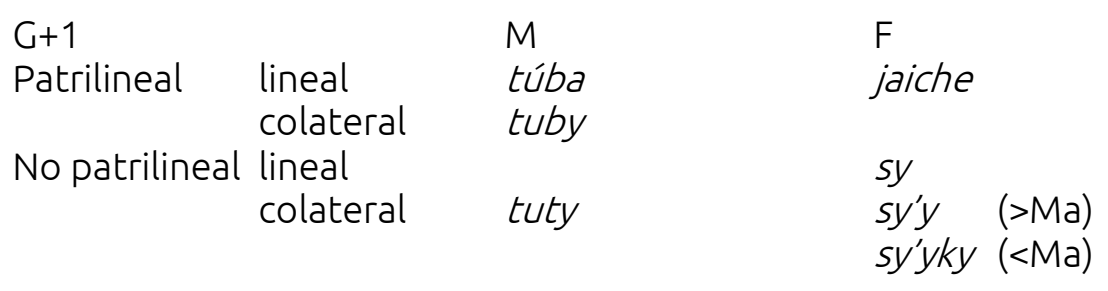

El cuadro puede leerse a partir de cuatro ejes. En un eje vertical los parientes se oponen por ser varones (túba, tuby, tuty) o mujeres (jaiche, sy, sy'y, sy'yky). En un segundo eje, horizontal, se forman dos clases de parientes, patrilineales (túba, tuby, jaiche) y no patrilineales (tuty, sy, sy'y, sy'yky). El eje horizontal presenta además una subespecificación 
interna, de acuerdo a la ascendencia lineal/colateral del pariente, pero el rasgo es funcional sólo en los varones patrilineales ( $t u ́ b a, t u b y)$ y en las mujeres no patrilineales ( $s y, s y^{\prime} y, s y^{\prime} y k y$ ). Por último, sólo las mujeres no patrilineales hacen una distinción ulterior, en función de la edad relativa del pariente ( $\left.s y s y^{\prime} y, s y^{\prime} y k y\right)$. Se trata de una subclase especial de parientes, ubicados en un tercer eje, la diagonal izquierda-derecha. En efecto, son los parientes de esta diagonal los que observan mayores distinciones. Según hemos postulado arriba, distinciones internas son una manifestación de la dimensión de espacialidad. Así, en la G+1 los varones patrilineales y las mujeres no patrilineales forman una subclase de parientes próximos. En una concepción de parentesco basada en la familia extensa patrilineal y sus aliados, el padre y su/s esposa/s, junto con los hermanos de éste y las esposas correspondientes, forman el grupo nuclear de Ego y constituyen sus parientes próximos en la $G+1$. Por otra parte los parientes de un cuarto eje, tuty y jaiche, en la diagonal derecha-izquierda, son tratados de manera más general, definidos con sólo dos rasgos. Siguiendo nuestro razonamiento, tuty y jaiche son parientes social o espacialmente "lejanos", que forman matrimonios externos al grupo nuclear de Ego. Nótese que una forma de entender estas relaciones diagonales también puede ser clasificando como "paralelos" a los parientes próximos (diagonal izquierda-derecha), y "cruzados" a los parientes lejanos (diagonal derecha-izquierda). No obstante creemos que la idea de espacialidad debe mantenerse separada de estas categorías antropológicas tradicionales, y concebirse en interacción con aquellas más bien que determinada por ellas. Esto es así ya que, como veremos, hay parientes paralelos en las G0 y la G-1 que son tratados del mismo modo que los parientes cruzados en términos de espacialidad.

El grupo de lexemas arriba puede a su vez simplificarse desde una perspectiva diacrónica. En efecto, las palabras que indican "colateralidad" son claramente compuestos, es decir palabras formadas a partir de raíces simples, indicio de que constituyen desarrollos posteriores. En el caso de tuby 'Hno.Pa' y sy'y'Hna>.Ma', se descubre la forma (')y pospuesta a los lexemas básicos túb(a) y sy, siendo (')y un intensificador más tarde devenido en diminutivo. ${ }^{12}$ Por otra parte el modificador ky 'tierno', en la forma $s y^{\prime} y$-ky, introduce una distinción ulterior, hecha ya a partir de una forma compuesta, sy-'y. Esto revela que el contenido "lineal/colateral" y "edad con respecto a la Ma" son evolutivamente posteriores, habiendo existido primero una oposición entre términos simples que distinguían a los progenitores ( $t u ́ b a, s y)$ de los afines (tuty, jaiche). Téngase en cuenta que, como vimos en $\S 3$, los lexemas tuby y sy'yky no constan en tupí y son propios del guaraní, lo cual indica que el cambio es posterior a la separación entre ambos grupos lingüísticos.

\footnotetext{
${ }^{12}$ Los autores del ALGR brindan otra explicación plausible: "el concepto 'tío paterno', t-uvy 'tío' cheruvy 'mi tío', se explica como compuesto de las raíces tu 'padre' y t-yvy, che-ryvy 'mi hermano menor'. De tu+ - (y)vyse ha formado tuvy'padre como hermano menor' (ALGR, p. 285).
} 


\section{LA DIMENSIÓN DE LA “GENERACIÓN"}

Túba y tuty pueden emplearse también para otras generaciones. Esto significa que el rasgo de "generación" es neutralizable. En la teoría semántica estructural la neutralización involucra un tipo de oposición en donde uno de los términos puede adquirir el rasgo distintivo de aquel al cual se opone exclusivamente, rasgo que se considera "marcado" en el segundo término y "no marcado" en el primero. Es necesario entonces identificar los paradigmas donde estos términos forman oposiciones exclusivas, neutralizables. Túba se opone a tuby exclusivamente por el rasgo "colateral" en el eje patrilineal. En tanto túba puede emplearse como sinónimo de tuby, esto es, para Hno.Pa, esto no ocurre a la inversa, y el término marcado de la oposición es tuby.

$\begin{array}{llll} & \text { patrilineal } & \text { hombre } & \text { colateral } \\ \text { túba } & + & + & \sim \\ \text { tuby } & + & + & +\end{array}$

Por otra parte túba puede emplearse para un hombre de la G+2. Esto indica que el rasgo "generación" es neutral ( ) en túba por oposición a un término correlativo marcado para G+2, en este caso tamõiPa.Pa, Pa.Ma, etc. (cf. § 3).

$\begin{array}{llll} & \text { patrilineal } & \text { hombre } & \mathrm{G}+2 \\ \text { tamõi } & \sim & + & + \\ \text { túba } & + & + & \sim\end{array}$

Túba puede emplearse para un hombre patrilineal de la $\mathrm{G}+2$, en tanto tamõi siempre vale para un hombre de la G+2 (siendo indiferente la patrilinealidad). Con esto es túba el término menos específico en la parentela patrilineal. Su significado básico puede definirse como "el hombre (por antonomasia) de la familia de Ego", siendo los rasgos de generación y ascendencia posiblemente determinados por su categoría de "hombre", en guaraní ava, voz que indica no sólo la adultez del varón y su capacidad para tener esposas, sino también su virilidad guerrera (por oposición a los varones de la generación inferior o kuimba'e 'muchacho' y de la generación superior o tamõi "abuelo/anciano"). Con respecto a tuty, Hno.Ma, éste es el término correlativo, genérico, para los parientes afines varones de la G+1 y G0. Otros términos del grupo de los afines, jýra y jetipe (primos/as, sobrinos/as cruzados de Ego) también valen para dos generaciones, en este caso para G0 y G-1 (cf. § 3.13 y $\S$ 3.14). Esta situación, común a los parientes no patrilineales, indica que el contenido "generación" se ha segmentado de manera diferente en un subsistema propio de esta clase de parientes. El siguiente esquema muestra esta situación: 


$\begin{array}{llllc} & \text { No patrilineal } & \text { Generación } & \text { Sexo } & \text { Sexo del hablante } \\ \text { tuty } & + & \mathrm{G}+1, \mathrm{G} 0 & \mathrm{M} & \sim \\ \text { jýra } & + & \mathrm{G} 0, \mathrm{G}-1 & \mathrm{M} & \mathrm{M} \\ \text { jetipe } & + & \mathrm{G} 0, \mathrm{G}-1 & \mathrm{~F} & \mathrm{M}\end{array}$

El significado de tutypuede extenderse a la G0, donde puede ser sinónimo de jýra, y el significado de jýra sólo es privativo en la G-1. Jetipe por su parte vale para mujeres afines de la G0 y G-1. Hay además una diferencia a tener en cuenta, y es que jýra y jetipe son términos exclusivos del habla del varón. Tuty significa de este modo "hombre afín a Ego, de la generación superior a la generación de Ego, o de la misma generación", en tanto jýra es un "hombre afín a Ego varón, de la misma generación de Ego varón, o de una generación inferior". Jetipe una "mujer afín a Ego varón, de la misma generación de Ego varón, o de una generación inferior".

\section{LAS GENERACIONES G+2 Y G-2}

En el caso de tamõi 'abuelo' y jarýi 'abuela', la lengua clasifica en un mismo grupo a los ancestros de la familia tanto del padre como de la madre, distinguiéndolos sólo por su sexo. La patrilinealidad o su ausencia no son relevantes, y según las fuentes todos los varones y mujeres ancianos de la aldea pueden ser tamõio jarýi respectivamente.

$\begin{array}{lll}\text { Sexo del pariente } & M & \mathrm{~F} \\ \mathrm{G}+2 & \text { tamõi } & \text { jarýi }\end{array}$

Así, de acuerdo con su función léxica, tamõies sólo un 'hombre de la G+2' y jarýiuna 'mujer de la G+2'. Tampoco es relevante la patrilinealidad en la G-2, donde la distinción más importante es la de "sexo de Ego" o "sexo del hablante", sin distinguir el sexo del pariente.

Sexo del hablante $M$

$\mathrm{G}-2$ temymyno temiarirõ

Así tenemos temymyno con el significado básico de 'pariente del varón de la G-2' y temiarirõ como 'pariente de la mujer de la G-2'. Con esto, las generaciones más ancianas y las más jóvenes son las únicas indiferentes a la patrilinealidad. Esto se explica porque en estas generaciones no eran infrecuente las alianzas matrimoniales (sobre todo entre ancianos y muchachas) así como el intercambio sexual "de prueba" (entre muchachos y ancianas, FERNANDES 1963, p. 153). Así el sistema trata a ambas generaciones como afines. Con todo, no está claro cómo se manifiesta la espacialidad en estos parientes. De hecho, el uso de fórmulas de respeto para parientes de la generación anciana (§ 6) podría arrojar algunas pistas.

Revista Mundaú, 2018, n.4, p.52-79 


\section{LA GENERACIÓN GO}

Las dimensiones de "filiación" y "sexo del pariente", igual que en $\mathrm{G}+1$, sirven para organizar a los parientes de la G0. Para la G0, así como para las G-1 y G-2, es pertinente además el rasgo "sexo del hablante". Los parientes de Ego masculino para G+1 son:

$\begin{array}{lll}\text { G0/EgoM } & M & F \\ \text { Patrilineal } & \text { tyke'y } & \text { (>Ego) } \\ \text { tyby } & (<\text { Ego }) & \text { teindy } \\ \text { No patrilineal jýra } & & \text { jetipe }\end{array}$

Los ejes de la filiación y el sexo establecen las posiciones principales, diferenciando entre varones y mujeres de ascendencia paterna (hijos e hijas del Pa. y de los Hno.Pa), y varones y mujeres descendientes de un hombre ajeno a la familia del padre (normalmente hijos e hijas del Hno.Ma y de la Hna.Pa). ${ }^{13}$ Por otra parte reaparece la subespecificación de "edad relativa", "> a Ego" o "> a Ego", aquí para los consanguíneos del varón. Esta característica es a nuestro modo de ver otra manifestación de la dimensión de "espacialidad", que también permitió interpretar las distinciones en ciertos parientes de la G+1. De acuerdo con esta lógica, sólo los hermanos y primos paralelos de Ego son concebidos como "parientes próximos", y en consecuencia clasificados en diferentes jerarquías internas. El hecho de que tyke'y pueda servir también para designar el Ho.Hno(>Ego) (ver § 3.10), indicaría que no es la generación o la edad del pariente lo que justifica esta subespecificación, sino probablemente una concepción hereditaria de la primogenitura. Por otra parte las hermanas de Ego, al igual que los parientes afines, son tratadas con un único término. Siguiendo nuestra hipótesis, este hecho se apoya en contenidos culturales vinculados a la espacialidad. Así, pese a su estatus patrilineal, teindyes tratada como potencial pariente lejana pues su destino es ser entregada a un hombre de otra familia y su descendencia tampoco pertenecerá a la línea patrilineal. Esto es paralelo al tratamiento que recibe jaiche Hna.Pa en la G+1. Más adelante veremos que esta hipótesis se verifica también a nivel de la flexión nominal del término (cf. § 5). Jýray jetipe por su carácter de afines se encuentran también poco especificados, elemento que parece propio de los parientes lejanos.

En el habla femenina, por su parte, el subsistema posee ciertas asimetrías con respecto al propio del habla masculina, siendo el principal que no ha lexicalizado la oposición entre parientes patrilineales y no patrilineales (pues jýra y jetipe son términos de Ego varón). En consecuencia la mujer no posee lexemas simples para designar a los afines de su misma

\footnotetext{
${ }^{13}$ La irrelevancia de la madre en el estatus parental de los hijos es destacada por Anchieta. Los hijos que los hombres tenían con las esclavas de otros pueblos eran considerados consanguíneos, en cambio el destino de los hijos concebidos por mujeres guaraníes con cautivos era la muerte (ANCHIETA, 1846, p. 259-260; ver también nota 7).
} 
generación (sus primos y primas cruzados). Así parece que, al menos desde un punto de vista léxico, la mujer contrapone sus "consanguíneos" a "todos los demás", incluyendo en esta última categoría tanto a los afines como a los "no parientes" (que son potenciales enemigos). El subsistema se compone de los siguientes términos:

\begin{tabular}{|c|c|c|}
\hline G0/Ego F & $M$ & $\mathrm{~F}$ \\
\hline $\begin{aligned} \text { Patrilineal } & >\text { Ego } \\
& <\text { Ego }\end{aligned}$ & $\begin{array}{l}\text { kyvy } \\
\text { kyvyky }\end{array}$ & $\begin{array}{l}\text { tyke } \\
\text { kypy'y }\end{array}$ \\
\hline
\end{tabular}

Por otra parte, el rasgo de "edad relativa" se aplica a todas las posiciones, indicando, de acuerdo con nuestra hipótesis, que tanto los hermanos como las hermanas de la mujer configuran sus parientes próximos. No obstante a la luz del análisis morfológico veremos que otra interpretación es también posible (§ 5).

De hecho en algunas fuentes constan expresiones que las mujeres podrían usar para referirse a sus parientes de la misma generación (típicamente primos). Estas se encuentran especialmente detalladas en Mo.V. y en Mo.C (aunque no en Mo.T.). Las mismas poseen las siguientes características: 1) son términos descriptivos, compuestos a partir de otros términos de parentesco, 2) son expresiones no marcadas con respecto a la dimensión "sexo del hablante", es decir pueden ser usadas por varones y por mujeres, 3) no constan para el tupí ni para el kaiowá ni el mbyá contemporáneos, sino sólo para el guaraní antiguo, 4) algunas funcionan como variantes (sinónimos parciales) de términos simples del parentesco de la G0. El siguiente cuadro muestra las expresiones, su significado, y los términos que pueden considerarse variantes:

\section{Expresión}

tuby ra'y
tuby rajy
jaiche memby
$\sim$ kuimba'e
$\sim$ kuña
tuty ra'y
tuty rajy
sy'y memby
$\sim$ kuimba'e
$\sim$ kuña

Significado

Ho.Hno.Pa Ha.Hno.Pa

Ho.Hna.Pa

Ha.Hna.Pa

Ho.Hno.Ma

Ha.Hno.Ma

Ho.Hna.Ma

Ha.Hna.Ma

$\begin{array}{ll} & \text { Variant } \\ \begin{array}{ll}\text { H. masculina } \\ \text { tyke'y tyby } \\ \text { teindy }\end{array} & \\ & \\ \text { jýra } & \text { tuty } \\ \text { jetipe } & \text { tuty } \\ \text { jýra } & \\ \text { jetipe } & \\ \text { tyke'y tyby } & \\ \text { teindy } & \end{array}$

\section{H. femenina kyby kybyky tyke kypy'y}

En las expresiones se destaca su formación a partir de términos de la G+1 para parientes colaterales (tuby Hno.Pa, jaiche Hna.Pa, tutyHno.Ma, sy'y Hna.Ma) modificados con las diferentes voces para "hijo" e "hija" del pariente varón (ta'y, tajy) y de la parienta mujer (memby). El primo hijo de la parienta mujer es especificado a su turno con modificadores kuimba'e 'varón' y kuña 'mujer' (dada la neutralidad de memby para el sexo del referente). Con esto las diferentes clases de primos quedan bien diferenciadas, no sólo en tanto su 
filiación, sino también en tanto generación (típicamente G0) y sexo. El hecho de no constatarse estas expresiones en las variantes actuales del guaraní (kaiowá, mbyá), y de sólo existir en Montoya, hacen pensar que se tratan de desarrollos hechos por los padres jesuitas, quizás a partir de usos ya existentes entre los indígenas (CERNO, 2018, en prensa). No obstante usos descriptivos semejantes para los primos cruzados se registran en arawete (VIVEIROS DE CASTRO, 1993, p. 158-159), y confirmarían un origen interno. En araweté se trata de estilos o preferencias del habla, en el sentido de variantes perifrásticas para especificar la relación ${ }^{14}$. Del mismo modo, nos parece que en guaraní antiguo estas expresiones estuvieron vinculadas a necesidades del contexto comunicativo, no siendo necesariamente parte de una norma tradicional de distinguir entre clases de primos. Desde un punto de vista léxico, la mujer contó con un sistema muy restringido, en donde sólo se distinguen las mujeres de los hombres consanguíneos de su propia generación, es decir, sólo aquellos parientes donde no es posible el matrimonio.

\section{LA GENERACIÓN G-1}

En la G-1 el hombre clasifica sus hijos/as e hijos/as de sus hermanos en la misma categoría. Se trata de la descendencia de los parientes patrilineales de la G0. A este grupo se oponen los sobrinos cruzados del varón que, como ya hemos visto, clasifican como afines. Nótese que se trata de los hijos e hijas de las hermanas/primas paralelas de Ego varón. Por otra parte estos sobrinos no se distinguen de los primos cruzados de Ego varón, dado el alcance generacional de los términos jýra y jetipe (§ 4.2.2). En su forma más simple el subsistema se aprecia de la siguiente manera:

$\begin{array}{lll}\text { G-1/Ego M } & M & F \\ \text { Patrilineal } & \text { ta'y } & \text { tajy } \\ \text { No patrilineal } & \text { jýra } & \text { jetipe }\end{array}$

Montoya registra variantes del habla masculina que acentúan la reciprocidad de la relación entre Ego y sus hermanos/primos paralelos con respecto a sus hijos, y que permiten marcar diferencias internas. Estas variantes se forman con el prefijo jo- 'recíproco', más la raíz para "hijo" e "hija": jo-a'y 'nuestros hijos comunes [entre los hermanos varones]' y jo-ajy 'nuestras hijas comunes [entre los hermanos varones]'. Estos usos especializados indican la dimensión de la espacialidad, siendo la descendencia de Ego y sus hermanos concebida en

\footnotetext{
${ }^{14}$ También en araweté se constata la inexistencia de términos exclusivos para los primos cruzados de la mujer, existiendo en cambio términos genéricos para personas "in a marriageable position". El término tiwã, por ejemplo, "it is little used, even for reference, for cross-cousins, who are normally designated by descriptive forms ("mother's brother's child", "father's sister's child") (VIVEIROS DE CASTRO, 1993, p. 158-159).
} 
conjunto como parientes próximos, pertenecientes al grupo nuclear de Ego, por contraste con los parientes no patrilineales.

La mujer por su parte clasifica sus hijos con los hijos de sus hermanas/primas paralelas, diferenciándolos de los sobrinos hijos de sus hermanos/primos paralelos. Igual que para G0 del habla femenina, existen menos términos que en el habla masculina. Aquí se neutraliza la dimensión de "sexo del pariente":

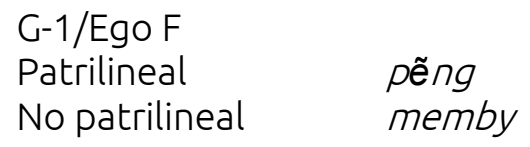

Lo más destacado de esta estructura es que memby'hijo/a de Ego femenino e hijo/a de sus hermanas' adquiere el rasgo de pariente "no patrilineal". En efecto, los hijos de la mujer y de sus hermanas se oponen a los hijos de sus hermanos varones porque, dada la regla de la descendencia por vía masculina, sus hijos no forman parte de la familia extensa de Ego femenino, sino que caen bajo la influencia del te'ýi de su esposo. Recordemos también que los hijos de la mujer serán para los hermanos de ésta sus afines, jýra y jetipe, es decir potenciales cuñados/esposas. La mujer tiene además la posibilidad de denotar el sexo de sus hijos con los modificadores kuimba'e 'muchacho' y kuña 'mujer', así che memby kuimba'e 'mi hijo varón' y che memby kuña 'mi hija mujer'. Además tiene un término para designar exclusivamente a los hijos varones de sus hermanas, memby ra'yse 'mi sobrino varón, hijo de mi hermana'. Comparando con las posibilidades expresivas de Ego varón surge que la mujer puede distinguir mejor los parientes "no patrilineales" de la G-1, de lo que surge que sus parientes próximos (después del matrimonio) para esta generación son los del téýi del esposo. En efecto memby es para la mujer un pariente próximo, aunque no patrilineal, en tanto pẽng indica patrilinealidad pero connota lejanía o distancia social.

\section{EVIDENCIAS GRAMATICALES}

Arriba hemos propuesto que las distinciones fundamentales del parentesco guaraní son la generación, la filiación, el sexo del pariente, y el sexo del hablante, y que a estas distinciones se agrega un contenido de espacialidad que permite explicar la forma que adquieren ciertas estructuras, y que establece ciertas asociaciones concomitantes. Esta hipótesis puede sostenerse también en la observación de la morfología que toca a los lexemas de parentesco, concretamente de los alomorfos que acompañan la flexión de persona. En guaraní todos los nombres entran en dos clases según formen la relación de tercera persona "definida" con el prefijo $h$ - o con el prefijo $i$-, por ejemplo h-esa 'su ojo', pero i-po 'su mano'. Los nombres de la primera clase toman el prefijo r-en combinación con otros prefijos personales o en compuestos (che-r-esa 'mi ojo', teju-r-esa 'ojo del lagarto') en tanto 
la manifestación de la segunda clase en el mismo contexto es simplemente un morfema cero (che- $\varnothing$-po 'mi mano', ava- $\varnothing-p o$ 'mano del hombre'). Diferentes autores llaman en este sentido "nombres de clase r-" al primer grupo y "nombres de clase $\varnothing$ " al segundo. Se ha argumentado además que no hay una motivación semántica sino que la clasificación de un nombre en una u otra clase es arbitraria (JENSEN, 1998, p. 498-499) ${ }^{15}$. Existe también una forma para una tercera persona "indefinida", realizada con el morfema $t$ - en los nombres de clase r- (t-esa "ojo") y con $\varnothing$ - otra vez en los nombres de clase $\varnothing$ ( $\varnothing$-po 'mano'). Una última posibilidad es la tercera persona "reflexiva" con el prefijo gu- para los nombres de clase r(gu-esa 'su propio ojo') y con o-para los nombres de clase $\varnothing$ (o-po 'su propia mano'). Existe además una subclase dentro de la clase r-, cuyos miembros no conocen la forma $h$-, con lo que la 3 persona no distingue la tercera persona definida, por ejemplo "su padre", de la indefinida, "padre" y ambos contenidos son expresados con la forma t-. Una buena parte de los nombres de parentesco entran en esta subclase (MONTOYA, 1640b, p. 9-11; ANCHIETA, 1595 [1874], p. 18-21), aunque como mostraremos, no al azar. En el siguiente cuadro vemos el léxico de parentesco para generación G2 y G1, distinguiendo las dos clases morfológicas y, dentro de la primera, dos subclases, con o sin distinción entre 3 persona definida y 3 persona indefinida.

\begin{tabular}{|c|c|c|}
\hline \multicolumn{2}{|l|}{ Clase r- } & \multirow[t]{2}{*}{ Clase Ø- } \\
\hline $\begin{array}{l}\text { Con distinción 3p. } \\
\text { definida/indefinida }\end{array}$ & $\begin{array}{l}\text { Sin distinción } 3 \text { p. } \\
\text { definida/indefinida }\end{array}$ & \\
\hline Tamõi & $\begin{array}{l}\text { túba } \\
\text { tuby }\end{array}$ & $\begin{array}{l}\text { jarýi } \\
\text { tuty } \\
\text { jaiche } \\
\text { sy } \\
\text { sy'y } \sim \text { sy'yky }\end{array}$ \\
\hline
\end{tabular}

El cuadro muestra que los nombres de la clase r- incluyen sólo parientes varones y que la clase $\varnothing$ incluye a los parientes que cumplen alguna de las condiciones de ser i) mujeres, o ii) afines. Así se explica la pertenencia de jaiche (mujer patrilineal) y tuty (hombre afín) en el subgrupo. Por otra parte entre los nombres de clase r-, tamõise distingue de túba (y de tuby) por la posibilidad de diferenciar entre h-amõi "su abuelo" y t-amõi "abuelo", en tanto para túba y tuby esta distinción queda formalmente excluida. Recordemos que desde un punto de vista semántico la diferencia fundamental entre tamõipor un lado y túbay tuby por el otro es la marca de patrilinealidad en los dos últimos. Los nombres de clase $\varnothing$, por su parte, pueden flexionar tanto para referencia indefinida como para referencia definida. Nótese que tuty, pese a comenzar con la consonante $t$, forma la tercera persona definida con

\footnotetext{
${ }^{15}$ La clase que lleva la marca $r$-incluye sólo nombres "inalienables", en tanto la que no lleva $r$-, posee tanto nombres "inalienables" como "alienables".
} 
i-tuty ('su tío materno'), diferenciándose de $\varnothing$-tuty ('tío materno"), como corresponde a los lexemas de su clase. En las G0 y G1 los lexemas del habla masculina siguen este mismo ordenamiento.

\begin{tabular}{|l|l|l|}
\hline Clase r- & Clase $\emptyset$ - \\
\hline $\begin{array}{l}\text { Con distinción 3p. } \\
\text { definida/indefinida }\end{array}$ & $\begin{array}{l}\text { Sin distinción 3p. } \\
\text { definida/indefinida }\end{array}$ & \\
\hline $\begin{array}{l}\text { teindy } \\
\text { temyéy } \text { tyvy } \\
\text { ta'y } \\
\text { tajy }\end{array}$ & $\begin{array}{l}\text { jýra } \\
\text { jetipe }\end{array}$ \\
\hline
\end{tabular}

Obsérvese que aquí también los nombres que forman la clase $\varnothing$ corresponden a los parientes afines, en tanto los que corresponden a la clase r- son patrilineales, con excepción del término no marcado para filiación temymynõ 'nieto/nieta del varón'. La hermana de Ego, teindy, clasifica con temymynõ, hecho que se explica por su condición de pariente patrilineal femenina, como jaiche, cuya descendencia no va a formar parte de la familia de Ego. Tajy por su parte, 'hija' de Ego masculino, otra pariente patrilineal mujer, clasifica con los términos típicamente masculinos varones y patrilineales. Para explicar este hecho hay que recordar que la descendencia de su hija, en tanto miembro de la G-2, es ya indiferente a Ego desde el punto de vista de la filiación, lo que no ocurre con teindy.

En el léxico de la mujer se muestra un orden bastante diferente al que se observa en el léxico masculino:

\begin{tabular}{|l|l|l|}
\hline Clase r- & \multicolumn{2}{|l|}{ Clase $\emptyset$ - } \\
\hline $\begin{array}{l}\text { Con distinción 3p. } \\
\text { definida/indefinida }\end{array}$ & $\begin{array}{l}\text { Sin distinción 3p. } \\
\text { definida/indefinida }\end{array}$ & \\
\hline Temiarirõ & tyke & $\begin{array}{l}\text { kypy'y } \\
k y v y \sim k y v y k y \\
\text { memby } \\
\text { pẽng }\end{array}$ \\
\hline & & \\
\hline
\end{tabular}

Notablemente para la mujer los hermanos varones y la hermana menor, junto con los hijos y los sobrinos (paralelos y cruzados) clasifican dentro de la clase $\varnothing$, que en las otras generaciones y en el habla del varón incluye a los parientes afines. Nuestra explicación es que, pese a que en el nivel semántico tanto los hermanos y como las hermanas de la mujer son tratados como parientes próximos, en el plano morfológico la lengua los trata de la misma manera que a los parientes no patrilineales (aquí memby) o a los parientes lejanos (pẽng). De hecho los hermanos de la mujer (del mismo modo que la hermana del varón) son parientes potencialmente lejanos, destinados a pertenecer a diferentes familias extensas. Pese a todo, esto no explica el tratamiento separado de las hermanas, es decir la inclusión de kypy'y Hna<EgoF dentro de la clase $\varnothing$ y de tyke, Hna>EgoF en la clase r-. Nos parece que, 
como hemos argumentado, las diferencias entre miembros de la misma clase no marcaron edad sino jerarquía, y posiblemente tyke sea la forma más antigua para 'hermana (patrilinear)', siendo kypy'y una expresión con marcas semánticas hoy perdidas. ${ }^{16}$ Temiarirô, nietos/as de la mujer, representa un hecho paralelo a los nietos/as del varón.

\section{EVIDENCIAS PRAGMÁTICAS}

Otro plano en el que actúa la dimensión de la espacialidad es en el uso, concretamente en las fórmulas de respeto basadas en las expresiones pa'i y ha'i, formas alocutivas para 'padre' y 'madre' respectivamente, y que pueden usarse también con otras personas (Mo.T; Mo.C; AnA, p. 20) ${ }^{17}$. En la lexicografía de Montoya sólo se cuentan seis posibilidades de empleo de estas expresiones ${ }^{18}$, que a su turno muestran relaciones opositivas con los términos primarios. Estas formas pueden ordenarse de la siguiente manera:

\begin{tabular}{|c|c|c|c|c|c|c|}
\hline & & & $M$ & & & \\
\hline J+ & túba & $\sim$ & pa'i & sy & $\sim$ & ha'i \\
\hline $\mathrm{H}+$ & tuby & $\sim$ & pa'i tuby & $s y^{\prime} y$ & $\sim$ & ha'isy'y \\
\hline$j+2$ & tamõi & $\sim$ & pa'i ramõi & jarýi & $\sim$ & ha'i jarýi \\
\hline
\end{tabular}

Estas expresiones fueron sinónimos parciales, aunque con una marca distintiva en el término simple, el de la izquierda en cada par (túba, tuby, etc.), por ser más específico. El término de la derecha ( $p a^{\prime} i$, ha'iy sus modificadores), más general, puede usarse también con el sentido del término simple. Por otra parte, en las fuentes no consta la posibilidad del uso de pa'i y ha'i con los parientes que llamamos "lejanos" en la G+1, esto es *ha'i jaiche y *pa'i tuty serían formas inexistentes. Esto concuerda con nuestra visión, arriba expresada, de que existe un rasgo concomitante común a ciertos lexemas de mujeres patrilineales (jaiche, teindy) y a los parientes afines o "cruzados" (tuty, jýra, jetipe), hecho que se manifiesta como

\footnotetext{
${ }^{16}$ Recordemos que en algunas variedades kypy'y podía designar "hija de la hermana", lo que indica un origen no patrilineal (del mismo modo que memby).

17 Pa'í: "Padre, es palabra de respeto, y con ella nombrã a sus viejos, hechizeros, y gente graue, corresponde a (haí) madre" (Mo.T., no consta en Mo.C). Ha'i: "Madre natural, y aunque no lo sea, dizenlo á las mayores" (Mo.C), "Madre, lo que corresponde a Paî, padre" (Mo.T.).

${ }^{18}$ Anchieta da por su parte más términos alocutivos que Montoya: "Alguns outros nomes ha que guardão o mesmo, mas tem subintellecto o adjectivo meus em todos os casos, ut aî, minha mãi. 0 macho chama á irmã pei, guaupíra, minha irmã, e a menina sobrinha itô , titô, guaitô , a irmã ao irmão ai, guaiâ , o pai e mãi ao filho macho pia, ao pai ou senhor paî, a fêmea á sua senhora, ou qualquer mulher honrada, tape) o macho tapê, qualquer mulher diz guaía, mano, ou meu mano, uma mulher á outra quii, quinai, nai, mana, minha mana, et alia que deve de haver d'esta forma (ANCHIETA, 1874 [1595], p. 20-21).
} 
vimos en la distribución del rasgo colateral en la $\mathrm{G}+1$, en las marcas de "edad relativa" en la G0, y en la neutralización de ciertas categorías en el habla de la mujer.

\section{CONCLUSIONES}

Los términos de parentesco del guaraní antiguo se organizan de acuerdo con rasgos distintivos para las dimensiones de generación, patrilinealidad, sexo del pariente, sexo del hablante $y$, con menos productividad, con distinciones para edad relativa del pariente (con respecto a Ego y con respecto al pariente designado), y de colateralidad. El siguiente cuadro esquematiza las unidades léxicas y sus rasgos distintivos:

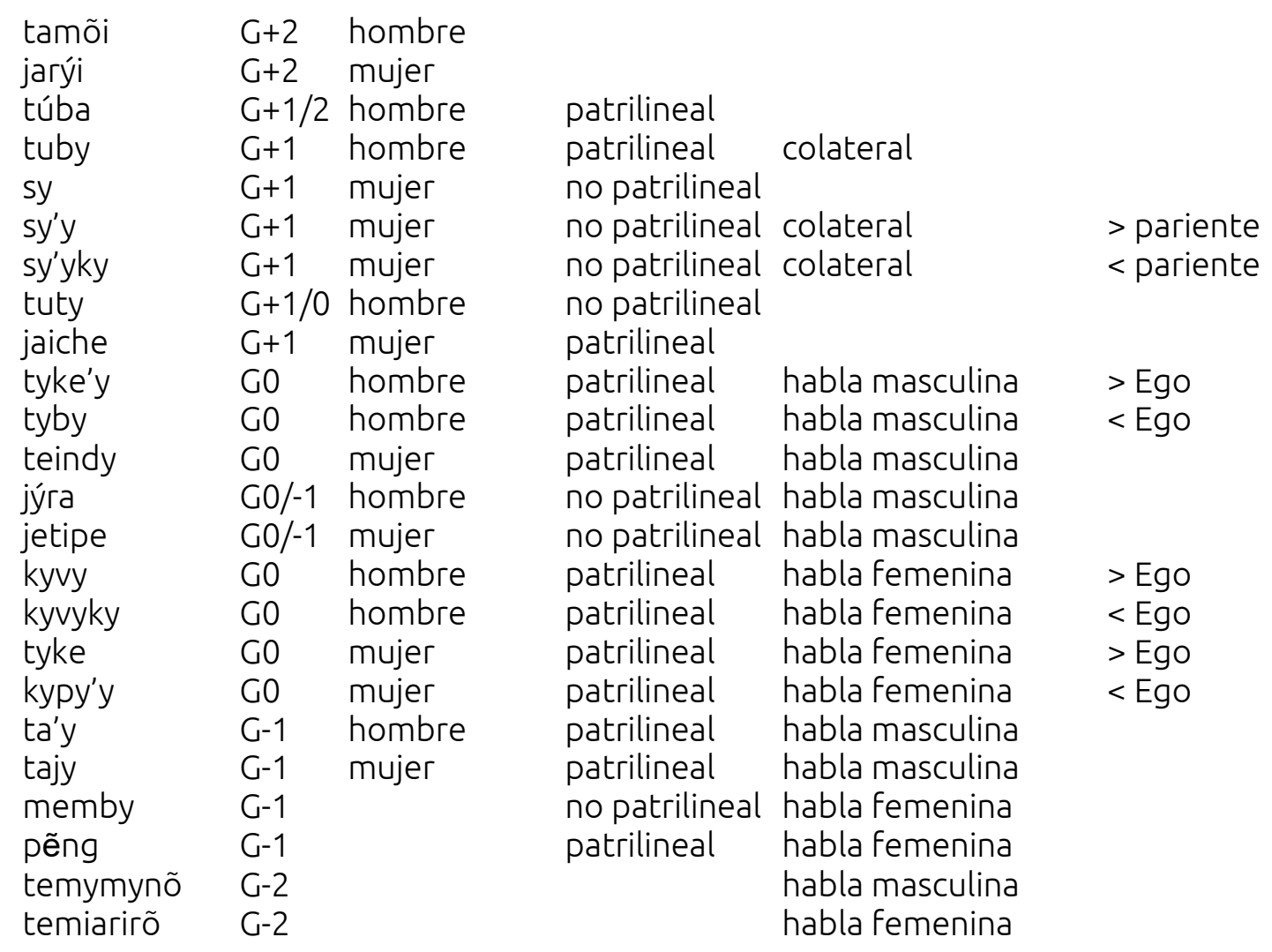

Entre tanto hemos mostrado que esta organización estructural, con sus instancias de neutralización y subespecificación de rasgos, se corresponde con un contenido semántico que llamamos "espacialidad". Este contenido, si bien no es distintivo, viene connotado por los valores sistémicos, sobre todo por las marcas de patrilinealidad y sexo del pariente. El cuadro de abajo esquematiza de manera aproximada los dos valores del contenido de espacialidad (pariente "cercano" y "lejano"), en interacción con los rasgos de patrilinealidad y sexo masculino. Los términos del habla masculina aparecen en negrita, los del habla femenina están subrayados. Los términos para abuelos y nietos quedan afuera por no llevar una marca 
de patrilinealidad. Algunos términos aparecen en posición ambigua, mostrando que la espacialidad constituye un continuo, no una categoría binaria.

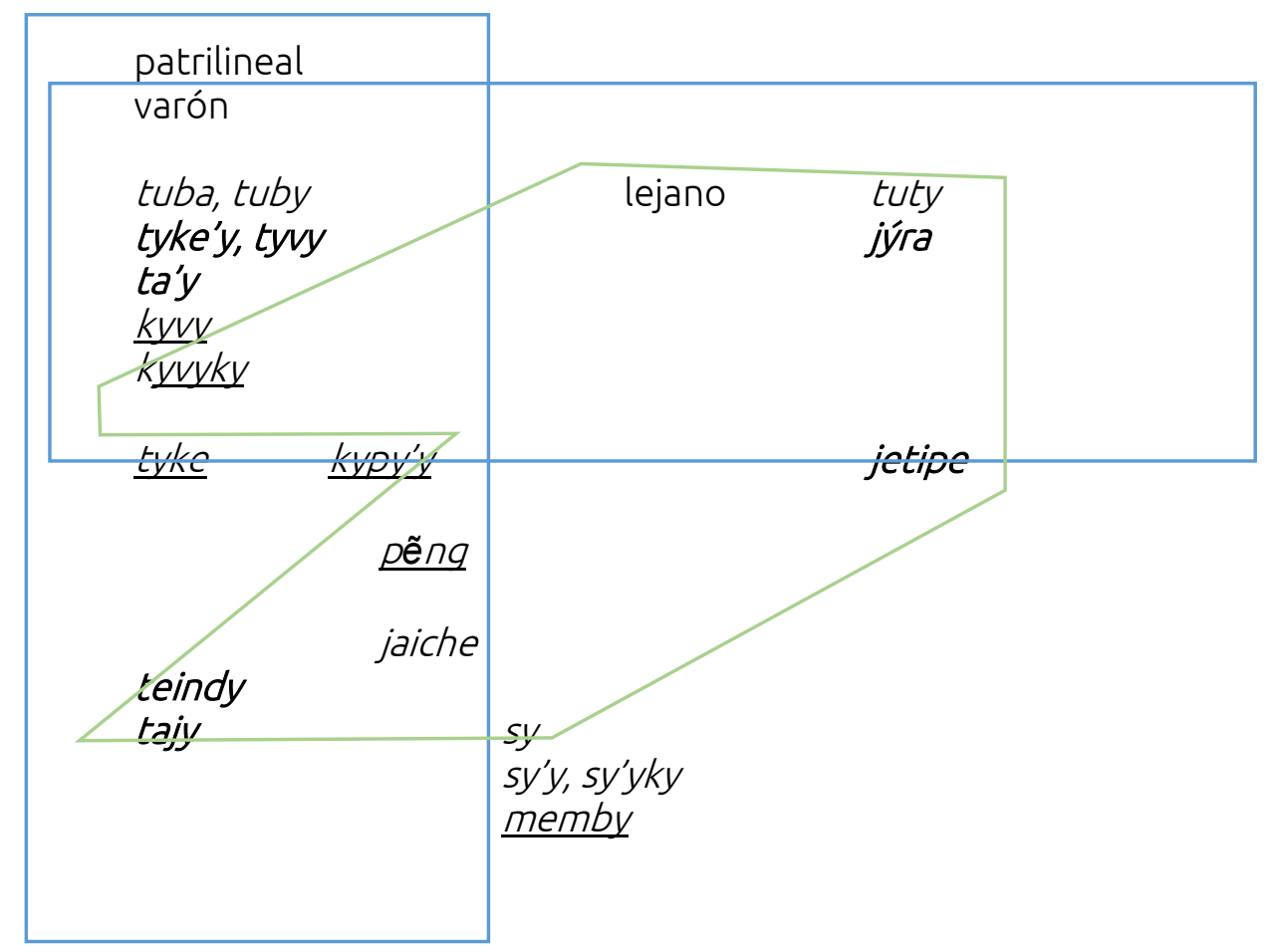

\section{REFERENCIAS}

ANCHIETA, Joseph de. Arte de grammatica da língua mais usada na costa do Brasil. Coimbra: António de Mariz, 1595, reed. Julius Platzmann. Leipzig: Teubner, 1874.

ANCHIETA, Joseph de. Informação dos casamentos dos indios do Brasil. En: Revista Trimensal de Historia e Geographia ou Jornal do Instituto Historico e Geographico Brasileiro, T. VIII, p. 254-262, 1846. Disponible en: http://biblio.etnolinguistica.org/anchieta_ 1846_casamentos. Consultado en: Enero de 2017.

[ALGR] DIETRICH, Wolf, Guido KALLFELL y Harald THUN (Org.). Atlas Lingüístico Guaraní-Románico (ALGR) T.Il: Léxico del parentesco. Kiel: Westensee Verlag, 2015.

ARAUJO, Antonio de S.J. Catecismo Brasilico da doutrina christiâa, Com o Ceremonial dos Sacramentos, \& mais actos Parochiaes. Composto Por Padres Doutos da Companhia de Jesus, Aperfeiçoado, \& dado a luz Pelo Padre Antonio de Araujo da mesma Companhia [...]. Lisboa: Miguel Deslandes, 1686.

BOSSERT, Federico; SENDÓN, Pablo F.; VILLAR, Diego. Introducción. Relevancia y actualidad de los estudios de parentesco en antropología. En: BOSSERT, Federico; SENDÓN, Pablo F.; VILLAR, Diego (eds.). El parentesco. Textos fundamentales. Buenos Aires: Biblos, 2012, p. 14-77. 
CERNO, Leonardo. Ruiz de Montoya y el parentesco guaraní. Primera parte: el parentesco por consanguinidad. Estudios Paraguayos, en prensa.

COSERIU, Eugenio. Por una semántica diacrónica estructural. In: COSERIU, Eugenio. Principios de semántica estructural. Madrid, Gredos, 1986.

DA SILVA AYROSA, Plínio M. Vocabulario na língua brasílica. Manuscrito português-tupí do seculo XVII, coordenado e prefaciado por Plínio M. da Silva Ayrosa. São Paulo: Imprensa Oficial do Estado, 1938 [s. $\mathrm{XVII}$.

DE MELLO, Flávia Cristina. Aetchá Nhanderukuery Karai Retarã. Entre deuses e animais: Xamanismo, Parentesco e Transformação entre os Chiripá e Mbyá-Guarani. Tesis Doctoral. Universidade Federal de Santa Catarina, 2006. Disponible en

https://repositorio.ufsc.br/bitstream/handle/123456789/88608/235594.pdf.

FERNANDES, Florestan. Organzação social dos tupinamba. $2^{\text {a }}$ edición revisada y ampliada. São Paulo: Difusão Européia do Livro, 1963.

GARCIA, Rodolfo. Nomes de parentesco em língua tupí. Anais da Biblioteca Nacional do Rio de Janeiro, v. LXIV, año 1942, p.178-189, 1944. Disponible en: http://biblio.etnolinguistica.org/garcia_1944_nomes. Consultado en: Octubre de 2017.

JENSEN, Cheryl. Comparative Tupí-Guaraní Morphosyntax. In: DERBYSHIRE, D. C. y PULLUM, G. K. (eds.), Handbook of Amazonian Languages, v. 4. Berlín / Nueva York: Mouton de Gruyter, 1998, p. 489618.

LARAIA, Roque de Barros. A estrutura do parentesco tupí. Rio de Janeiro: Museu Nacional do Rio Janeiro, s/a. Disponible em: http://de.scribd.com/document/156352965/A-Estrutura-Do-ParentescoTupi.Consultado en: Noviembre de 2016.

LARAIA, Roque de Barros. Os estudos do Parentesco no Brasil: BIB,v. 1, n. 23,1987, p. 3-17, 1987. Disponible en: http://www.anpocs.com/index.php/universo/acervo/biblioteca/periodicos/bib/bib23/386-os-estudos-de-parentesco-no-brasil/file. Consultado en: Agosto de 2017.

MARQUES PEREIRA, Levi. Parentesco e organização social kaiowá. Tesis de Maestría. Campinas: UNICAMP, 1999. Disponible en: http://repositorio. unicamp.br/handle/ REPOSIP /279531. Consultado en: Mayo de 2017.

MELIÀ, Bartomeu. La lengua guaraní en el Paraguay Colonial que contiene La creación de un lenguaje cristiano en las Reducciones de Guaraníes en el Paraguay. Asunción, CEPAG, [1969] 2003.

MELIÀ, Bartomeu; GRÜNBERG, Georg; GRÜNBERG, Friedl. Los Paĩ-Tavyterã. Etnografía guaraní del Paraguay contemporáneo. Asunción, CEADUC, [1976] 2008.

MURA, Fabio. À procura do "bom viver". Território, tradição de conhecimento e ecologia doméstica entre os kaiowa. Tesis doctoral. Río de Janeiro: Universidade Federal do Rio de Janeiro, 2006.

RUIZ DE MONTOYA, Antonio. Tesoro de la lengva gvarani. Compvesto por el padre Antonio Ruiz, de la Compañia de lesus [...]. Madrid, Juan Sánchez, 1639a. Disponible en: https://archive.org/details/ tesorodelalengua00ruiz. Consultado en: Septiembre de 2017. 
RUIZ DE MONTOYA, Antonio. Conqvista espiritval hecha por los religiosos de la Compañia de lesus, en las Prouincias del Paraguay, Parana, Vruguay, y Tape. Madrid: Imprenta del Reyno, 1639b. Disponible en: http://Fondosdigitales.us.es/fondos/libros/1837/1/ conquista-espiritual-hecha-por-los-religiosos-dela-compania-de-iesus-en-las-provincias-del-paraguay-parana-uruguay-y-tape. Consulado en: Agosto de 2017.

RUIZ DE MONTOYA, Antonio. Catecismo de la lengva gvarani, compvesto por el padre Antonio Ruyz, de la Compañia de lesus [...]. Madrid, Diego Díaz de la Carrera, 1640ª. Disponible en: https://archive.org/ details/catecismodelalen00ruiz. Consultado en: Noviembre de 2017.

RUIZ DE MONTOYA, Antonio. Arte, y bocabulario de la lengva gvarani. Compvesto por el padre Antonio Ruiz, de la Compañia de lesus [...]. Madrid, Juan Sánchez, 1640b. Disponible en: https://archive.org/details/bub_gb_TeTs0bFG-fcc. Consulado en: Agosto de 2017.

SCHMIEDL, Ulrich / Ulrico Schmidl. Reise in die La Plata-Gegend / 1534-1554. Straubing: JohannesTurmair-Gymnasiums, 2008.

VIVEIROS DE CASTRO, Eduardo. From the enemy's point of view. Humanity and Divinity in an Amazonian Society. Chicago/Londres: Chicago Press, 1993. 